\title{
A study of electromagnetic light propagation in a perovskite-based solar cell via a computational modelling approach
}

\author{
M N SHAIKH ${ }^{1}$, Q ZAFAR $^{2, *}$ (D) and A PAPADAKIS ${ }^{3}$ \\ ${ }^{1}$ Department of Electrical and Computer Engineering, COMSATS University Islamabad, Abottabad 22060, Pakistan \\ ${ }^{2}$ Department of Physics, School of Science, University of Management and Technology, Lahore 54000, Pakistan \\ ${ }^{3}$ Department of Electrical Engineering, School of Engineering, Frederick University, 1036 Nicosia, Cyprus \\ *Author for correspondence (qayyumzafar@gmail.com)
}

MS received 1 November 2018; accepted 20 December 2018; published online 23 May 2019

\begin{abstract}
Recently, there has been huge surge of scientific interest in organic-inorganic hybrid perovskite solar cells by virtue of their high efficiency and low cost fabrication procedures. Herein, we examine the light propagation inside a planar perovskite solar cell structure $\left(\mathrm{ITO} / \mathrm{TiO}_{2} / \mathrm{ZnO} / \mathrm{CH}_{3} \mathrm{NH}_{3} \mathrm{PbI}_{3} /\right.$ Spiro-OMeTAD/Al) by solving the Helmholtz equation in the finite element-frequency domain. The simulations were conducted using the COMSOL multiphysics finite element solver to carry out the two-dimensional optical modelling of simulated solar cells in the visible region. It has been observed that shorter wavelengths of light are significantly absorbed by the top region of the photoactive perovskite layer. Specifically, at a wavelength of $400 \mathrm{~nm}$, the effective optical power penetration decays to zero at only $40 \%$ of the overall length of the photoactive layer. This observation has been attributed to the high absorption coefficient of the $\mathrm{CH}_{3} \mathrm{NH}_{3} \mathrm{PbI}_{3}$ perovskite material at shorter wavelengths. However, at longer wavelengths, the incident light propagates deeper into the photoactive layer, reaching $100 \%$ penetration. Based on the numerical computation, a maximum generation rate of $\sim 3.43 \times 10^{23} \mathrm{~m}^{3} \mathrm{~s}^{-1}$ has been observed in the photoactive layer at a wavelength of $550 \mathrm{~nm}$.
\end{abstract}

Keywords. Optical simulation; finite element-frequency domain (FE-FD); Helmholtz equation; organic-inorganic hybrid perovskite; electromagnetic light propagation.

\section{Introduction}

Solar cells can effectively provide a virtually unlimited amount of clean renewable energy by harvesting sunlight into electrical power [1-3]. Recently, organometallic halide perovskite materials $\left(\mathrm{CH}_{3} \mathrm{NH}_{3} \mathrm{PbX}_{3}, \mathrm{X}=\mathrm{I}, \mathrm{Br}\right.$ and $\left.\mathrm{Cl}\right)$ have offered the promise of a breakthrough in the fabrication of next-generation solar cell devices [4-6]. These photoactive materials have attracted increasing attention due to their high charge carrier mobilities, high extinction coefficient, tuneable optical properties, ambipolar charge transport and significantly long electron-hole diffusion lengths [710]. Furthermore, these organic-inorganic hybrid perovskite materials are also compatible with facile, thermal budget and eco-benign fabrication techniques [8,11]. Kumar et al [12] have previously confirmed that the fabrication of organicinorganic perovskite solar cells is easy and cost-effective compared to the conventional Si-based solar cells. Based on these aforementioned unique properties and intensive worldwide cumulative R\&D efforts, the power conversion efficiencies (PCE) of perovskite solar cells have skyrocketed from 3 to 23\%, within a time-frame of 6 years [13-15].

To further improve the PCE of perovskite solar cells, several reviews thoroughly describe that material design, novel device architectures and efficient light trapping are among future viable pathways [14-16]. In particular, from the optical point of view, it is well understood that broadband absorption enhancement over the whole solar spectrum in perovskite solar cell devices may directly lead to lower recombination currents, higher open-circuit voltages and eventually higher PCE [17]. Therefore, to substantially increase the PCE of the solar cells, there exists a dire need to intensively investigate the optical properties of the photoactive perovskite materials. In this regard, the modelling of solar cells is as important as the experimental work since it allows the optimization of the optical design of solar cell devices and to understand the underlying physics of their operation [18].

Traditionally, to study the light propagation in bulk silicon solar cells, ray-tracing techniques have been widely utilized [19] and are based on the classical laws of geometrical optics. For instance, Brendel [20] studied light coupling into mechanically textured, encapsulated bulk silicon solar cells (thickness of $\sim 250 \mu \mathrm{m}$ ) by 3 -D ray tracing using the SUNRAYS software package. However, it is noteworthy that this technique may only be used whenever the geometrical size of the photoactive layer is much larger than the optical wavelength. For thin film solar cells, where the film thickness becomes comparable or smaller than the wavelength of light [21], light propagation cannot be adequately modelled by ray tracing and instead it is necessary to rigorously solve Maxwell's 
equations [22-24]. Therefore, numerical simulations capable of solving the Maxwell's equations and semiconductor equations (Poisson, continuity and drift-diffusion equations) are routinely performed to develop an understanding regarding the optoelectronic properties of solar cells [25,26]. Miyazaki et al [27] have investigated a hydrogenated amorphous silicon (a-Si:H) solar cell theoretically based on current continuity and Poisson equations.

Currently, there have been a number of numerical methods capable of simulating wave propagation in solar cell devices, such as the finite difference [28], finite volume [29] and finite element methods [30]. In the present study, we have simulated the light propagation through solar cells by utilizing a powerful computational technique, the solution of the Helmholtz equation in the finite element-frequency domain (FE-FD). In general, the finite element method is used to model discontinuities in light propagation in realistic, arbitrary, complex and non-uniform geometries, more accurately and efficiently as compared to finite difference and finite volume methods [31].

The objective of the present study is to numerically compute the electromagnetic field distribution in various layers of perovskite-based solar cells $\left(\mathrm{ITO} / \mathrm{TiO}_{2} / \mathrm{ZnO} / \mathrm{CH}_{3} \mathrm{NH}_{3} \mathrm{PbI}_{3} /\right.$ Spiro-OMeTAD/Al) in the visible region (wavelength of $400-700 \mathrm{~nm}$ ) of incident light. We intend to establish a multiphysics framework to obtain insight pertaining to light propagation, absorption and charge carrier's generation in the photoactive layer. The present optical model self-consistently solves the partial differential equation (i.e., Helmholtz equation) using the FE-FD method and allows for composition dependent material parameters. Herein, we are motivated to examine methylammonium lead iodide $\left(\mathrm{CH}_{3} \mathrm{NH}_{3} \mathrm{PbI}_{3}\right)$ as the photoactive perovskite layer by virtue of its interesting optoelectronic properties [32]. It is a semiconducting pigment with the direct band gap, $E_{\mathrm{g}}=1.55 \mathrm{eV}$ that allows efficient light absorption over the whole visible spectrum [33]. Furthermore, the excitons produced by light absorption in $\mathrm{CH}_{3} \mathrm{NH}_{3} \mathrm{PbI}_{3}$ have a weak binding energy of about $0.030 \mathrm{eV}$ [34], thereby allowing rapid dissociation of excitons into free charge carriers at room temperature.

\section{Numerical modelling approach}

The schematic cross-section of the simulated perovskitebased solar cell is depicted in figure 1a. The simulated solar cell (from top to bottom) consists of an indium tin oxide (ITO) transparent front contact $(80 \mathrm{~nm})$ deposited on the thin glass substrate $(150 \mathrm{~nm})$. The ITO thin film is followed by 120 and $150 \mathrm{~nm}$ thin electron transport layers of $\mathrm{TiO}_{2}$ and $\mathrm{ZnO}$, respectively. The photoactive layer consists of $500 \mathrm{~nm}$ thin methylammonium lead iodide $\left(\mathrm{CH}_{3} \mathrm{NH}_{3} \mathrm{PbI}_{3}\right)$ perovskite layer. A $100 \mathrm{~nm}$ hole transport layer of 2,2'-,7,7'-Tetrakis[ $N, N$-di(4-methoxyphenyl)amino]9,9-spirobifluorene (Spiro-OMeTAD) and aluminium metal back contacts have been utilized. The layer stack of the solar cell is in agreement with solar cell structures used in the literature [35-37]. In the present study, we have numerically modelled the ITO/ $\mathrm{TiO}_{2} / \mathrm{ZnO} / \mathrm{CH}_{3} \mathrm{NH}_{3} \mathrm{PbI}_{3} /$ Spiro-OMeTAD/Al planar structure to study the optical wave propagation within the layer stack of the simulated solar cell. Generally, the incident optical power is quantified by the standard spectral irradiance distribution curve (i.e., spectral irradiance as a function of wavelengths of incident photons). Herein, all FE-FD optical, simulations have been carried out in twodimensions (2D) for selected wavelengths ranging from 400 to $700 \mathrm{~nm}$. The solar irradiance at AM-1.5 for the selected wavelengths is depicted in figure $1 \mathrm{~b}$.

The transverse electromagnetic light impinging on the solar cell is normally divided into two polarization modes, the transverse electric (TE) and transverse magnetic (TM) [28]. Typically, when the electric field is perpendicular to the plane of incidence, then, it is associated with the TE mode. In contrast, when the electric field is in parallel with the plane of incidence, then, it is associated with the TM mode. In the case of TEM mode, however, both electric and magnetic fields are perpendicular to the plane of incidence. In the present numerical simulation, the calculations for electric field intensity of the incident light wave have been carried out using the wellestablished Helmholtz equation [38], depicted as equation (1):

$$
\nabla \times(\nabla \times E)-k_{\mathrm{o}}^{2} \varepsilon_{\mathrm{r}} E=0,
$$

where $k_{\mathrm{o}}$ is the wave vector of the incident light, $\varepsilon_{\mathrm{r}}$ the dielectric permittivity of the medium which is related to the complex refractive index $(n+i k)$ of photoactive materials. Therefore, the optical dispersion $n-k$ curves (as a function of wavelength) play a key role in carrying out an accurate optical simulation. Here, the optical constants ( $n$ and $k$ ) of each layer $(x, y$ and $z$ ) have been adapted from the literature [39-43], and used as input parameters in our simulator. The real part of the refractive index $n(\lambda)$ and extinction coefficient $k(\lambda)$ used in our study are depicted in figure $2 \mathrm{a}$ and $\mathrm{b}$, respectively, as a function of selected wavelengths.

In the optical approach of simulations, the effects of light reflection, transmission and absorption in every layer have been considered prior to light harvesting by the photoactive perovskite layer. It is well-understood that the wavelength dependent dielectric permittivity function defines the capacity of a material to absorb, reflect and transmit incident light [44]. Therefore, electromagnetic field's reflection $(R)$ and transmission $(T)$ coefficients have been facilely computed by the Fresnel equations, since the optical properties $n(\lambda)$ and $k(\lambda)$ of the constituent layers in solar cells are already known (figure $2 \mathrm{a}$ and $\mathrm{b}$ ). In this way, multiple diffusion of light inside the solar cell structure has been taken into consideration successfully. The optical power absorption inside the solar cell structure has been estimated using equation (2), as follows [45]:

$$
P(x)=(1-R) P_{\mathrm{o}} \exp (-\alpha x)
$$




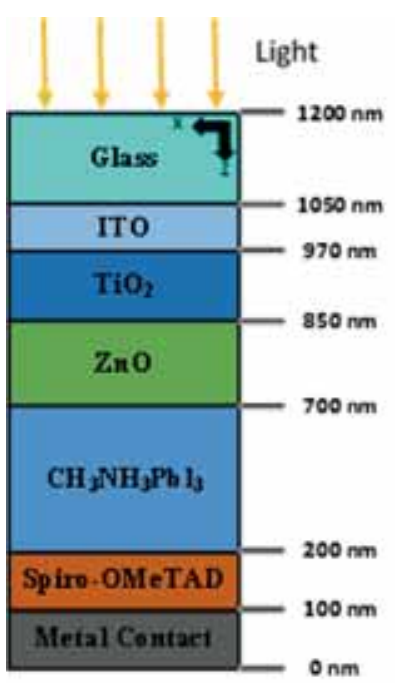

(a)

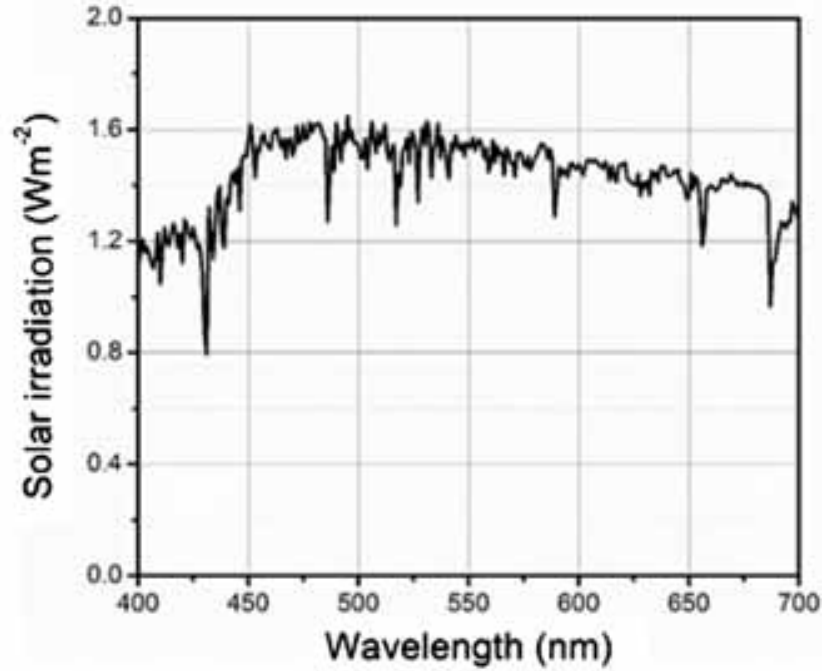

(b)

Figure 1. (a) Simulated perovskite-based solar cell structure and (b) selected wavelength solar irradiance at AM-1.5.

where $P(x)$ represents the optical power at any position $x$ inside the solar cell structure, whereas $P_{\mathrm{o}}$ represents the incident optical power. The term $\alpha$ represents the absorption coefficient and it is related to the extinction coefficient by the mathematical expression $\alpha=4 \pi k / \lambda$ [46]. The results of the absorption coefficient of various layers in solar cells as a function of $k(\lambda)$ are shown in figure 3.

The light impinging on the solar cell induces charge carrier generation in the photoactive layer of the cell structure by the absorption of photons [47-49]. The charge carrier generation is directly related to this internal power flux by the following relation [45]:

$$
G(x)=\frac{\alpha \lambda P(x)}{h c}
$$

where $c$ and $h$ represent the speed of light and Plank's constant, respectively. The term $G$ indicates charge carriers' generation rate at any position $x$ for a specific wavelength $\lambda$ of the incident light. Since, the generation rate is the number of carriers produced per second per volume inside the device, therefore, a final integration over the selected wavelength range has been performed to culminate total charge carrier generation inside the solar cell. It has been mathematically expressed by the following relation:

$$
G_{\text {eff }}=\int_{400 \mathrm{~nm}}^{700 \mathrm{~nm}} G(x, \lambda) d \lambda
$$

The photon flux $N$ is related to the incident optical power flux $P_{\mathrm{o}}$ as described below:

$$
P_{\mathrm{o}}=N q E_{\mathrm{p}}
$$

where $q$ and $E_{\mathrm{p}}$ represent the electronic charge and energy per incident photon in $E v$, respectively.

In optical simulations, apart from spectral irradiance, the photon flux $(N)$ is also required to calculate the internal quantum efficiency $\eta$ as a number of produced carriers per incident photons.

$$
\eta=G / N
$$

\section{Results and discussion}

To examine the optical behaviour of perovskite solar cells, electromagnetic analysis has been performed using the FEFD method. Visible-wavelength transverse electromagnetic light has been injected at normal incidence to the perovskite solar cell structure to quantify the expected light absorption by the photoactive layer. Using the Helmholtz equation (equation (1)), the electric field $(E)$ inside the perovskite solar cell has been computed using COMSOL Multiphysics software at five different wavelengths within the visible region. It can be observed from the 1-D electric field distribution (depicted in figure 4) that at shorter wavelengths, the electric field attenuates significantly inside the photoactive layer. This phenomenon is observed because light is strongly absorbed by the perovskite layer due to the significantly higher absorption coefficient of $\mathrm{CH}_{3} \mathrm{NH}_{3} \mathrm{PbI}_{3}$ at a wavelength of $400 \mathrm{~nm}$ (as previously shown in figure 3 ). However, as the light wavelength increases, weak absorption in $\mathrm{CH}_{3} \mathrm{NH}_{3} \mathrm{PbI}_{3}$ causes a slow decaying rate of the electric field intensity. This results in comparatively higher electric field distribution within the photoactive film. In the present FE-FD electromagnetic analysis, the cross-sectional profile for the electric field intensity has 


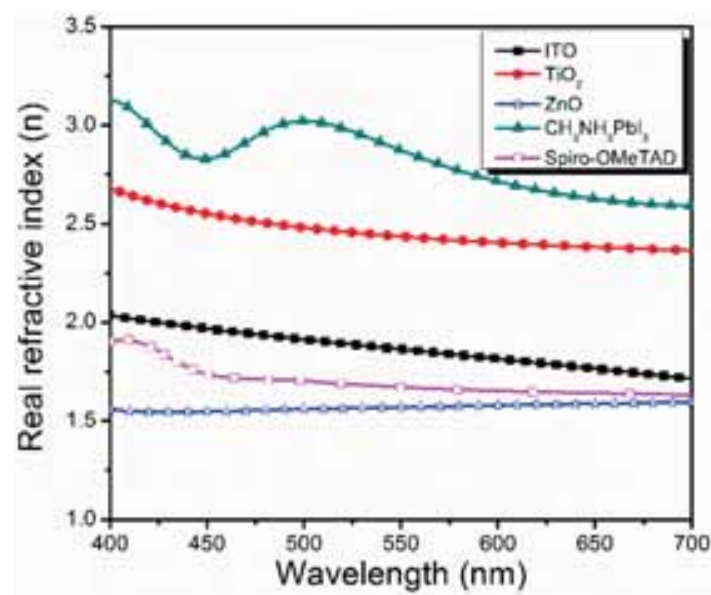

(a)

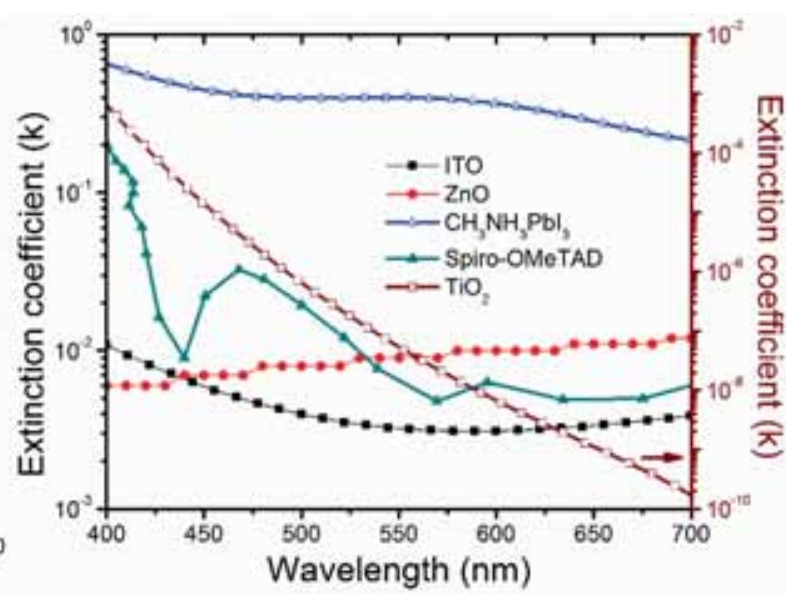

(b)

Figure 2. (a) Real component of the refractive index and (b) extinction coefficient, as a function of selected wavelengths.

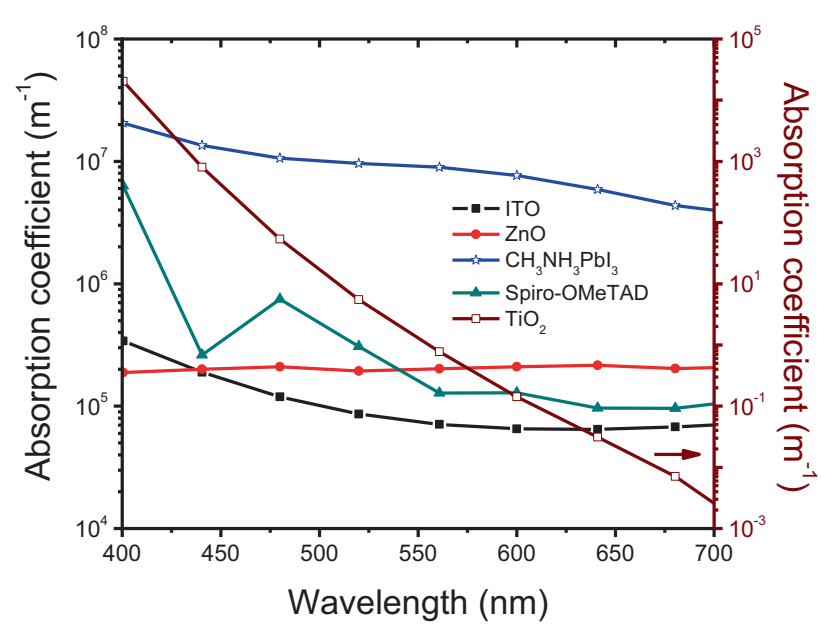

Figure 3. Absorption coefficient of constituent layers of the simulated solar cell at the selected wavelength range.

also been investigated in the $x-z$ plane of the solar cell. The 2D profile is depicted in figure 4 (inset: $a$ and $b$ ) and describes the electric field intensity distribution at wavelengths of 400 and $700 \mathrm{~nm}$, respectively. It can be clearly shown that the electric field inside the photoactive layer is relatively stronger at incident light with a wavelength of $700 \mathrm{~nm}$ as compared to the wavelength of $400 \mathrm{~nm}$. It is pertinent to mention that in the present study, the visible wavelength range has been used since the optical properties for perovskite solar cells are only currently available within the visible wavelength region. However, the developed simulator can also be applied for the broadband such as the UV-Vis-IR range as well, given that optoelectronic properties for the materials at these wavelengths are available from the literature.

In the present simulated solar cell, the incident light has to propagate first through the top transparent electrode and then through the n-type layers before reaching the photoactive $\mathrm{CH}_{3} \mathrm{NH}_{3} \mathrm{PbI}_{3}$ layer. As a consequence, assessing the optical propagation and losses within the solar cell structure is a critical issue. Using the FE-FD analysis, we have calculated the absorbed optical power inside the solar cell's structure based on equation (2). Since the horizontal line in figure 5 represents the vertical length of the simulated solar cell, it can be clearly observed that most of the incident energy first propagates downwardly along the $z$-direction before it is totally absorbed in the photoactive layer. Furthermore, it can also be observed from 1-D analysis (depicted in figure 5) that the optical power penetrates more deeply in the perovskite solar cell for longer wavelengths as compared to shorter wavelengths. Specifically, at a wavelength of $400 \mathrm{~nm}$, the effective optical power penetrates only to $40 \%$ of the overall length of the photoactive layer, whereas for $700 \mathrm{~nm}$, the significant optical power penetrates to nearly $100 \%$. From the cross-section of 2-D optical profile analysis (depicted in figure 5, inset: a and b), it can be clearly observed that for a light wavelength of $700 \mathrm{~nm}$, nearly the whole photon flux is trapped within the photoactive layer, indicating that the optical power absorption in the photoactive layer is significantly higher at shorter wavelength $(400 \mathrm{~nm})$.

Figure 6 shows the 1-D charge carrier generation profiles within the layer stack of the simulated solar cell for the normal incident light with wavelengths of 400, 475, 550, 625 and $700 \mathrm{~nm}$. Figure 6 shows that the contribution of charge carrier generation in the photoactive perovskite layer is considerably higher. This observation is reasonable since typically front contact, back metal contact, p-layer and n-layer do not contribute significantly to the charge carrier generation [23]. Furthermore, as previously observed in figures 4 and 5 , at short wavelengths, the electric field and absorbed optical power exhibit significantly small magnitudes in the bottom region of the perovskite layer, which shows that mostly the charge carriers are generated in the top region of the 


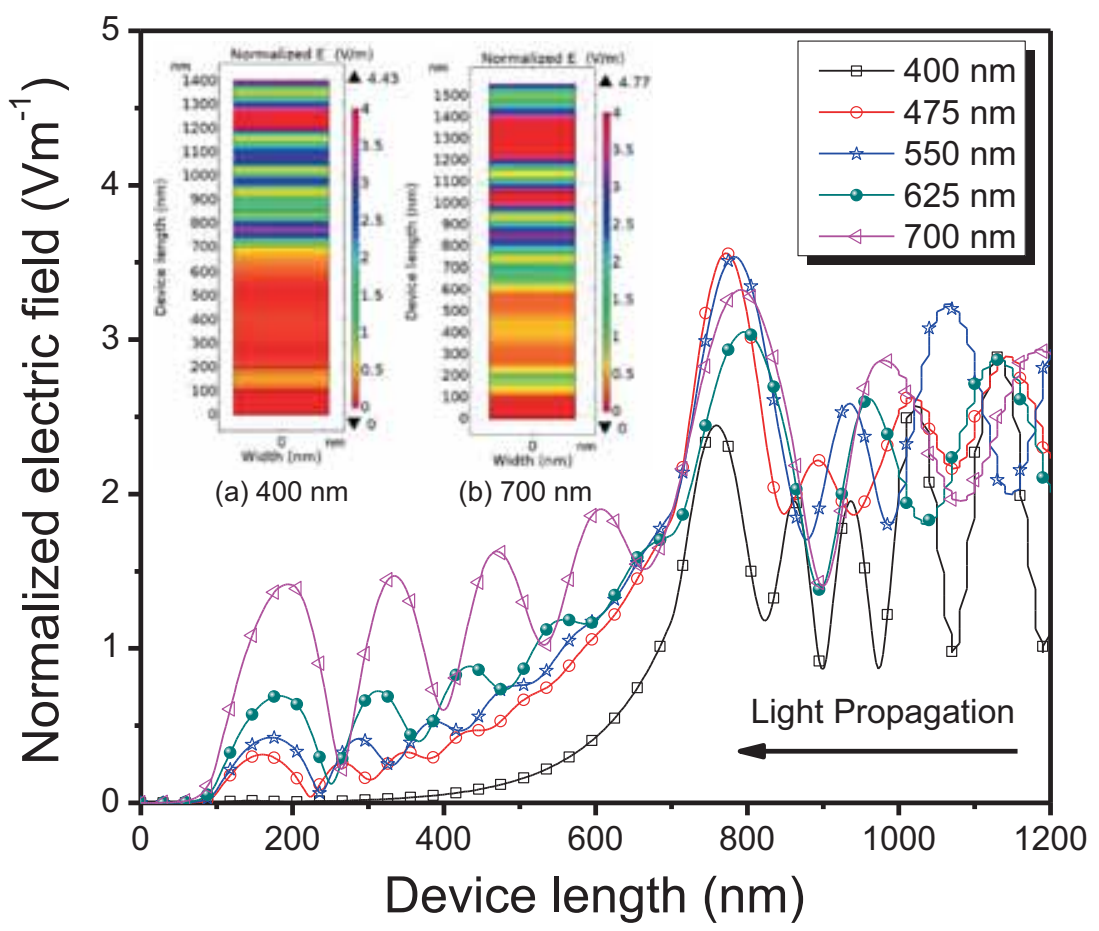

Figure 4. 1-D and (inset) 2-D cross-sectional normalized electric field distributions inside the layer stack of the simulated solar cell at varied incident wavelengths.

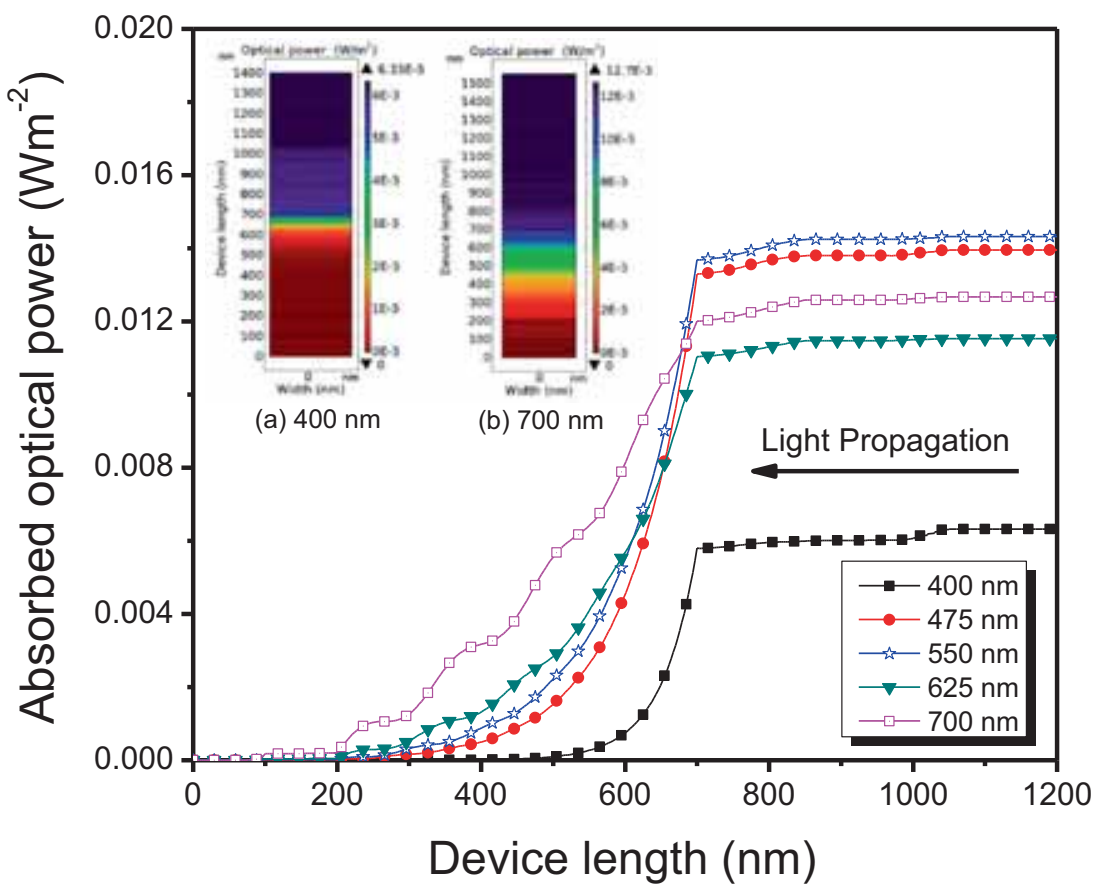

Figure 5. 1-D and (inset) 2-D cross-sectional absorbed optical power distributions inside the layer stack of the simulated solar cell at varied incident wavelengths.

photoactive layer. However, as the wavelength increases, the electric field intensity at the bottom of the perovskite layer also strengthens which leads to the charge carriers appearing in the whole region of the photoactive layer. A maximum generation rate of $3.43 \times 10^{23} \mathrm{~m}^{3} \mathrm{~s}^{-1}$ has been observed in the $\mathrm{CH}_{3} \mathrm{NH}_{3} \mathrm{PbI}_{3}$ photoactive layer at wavelength of 


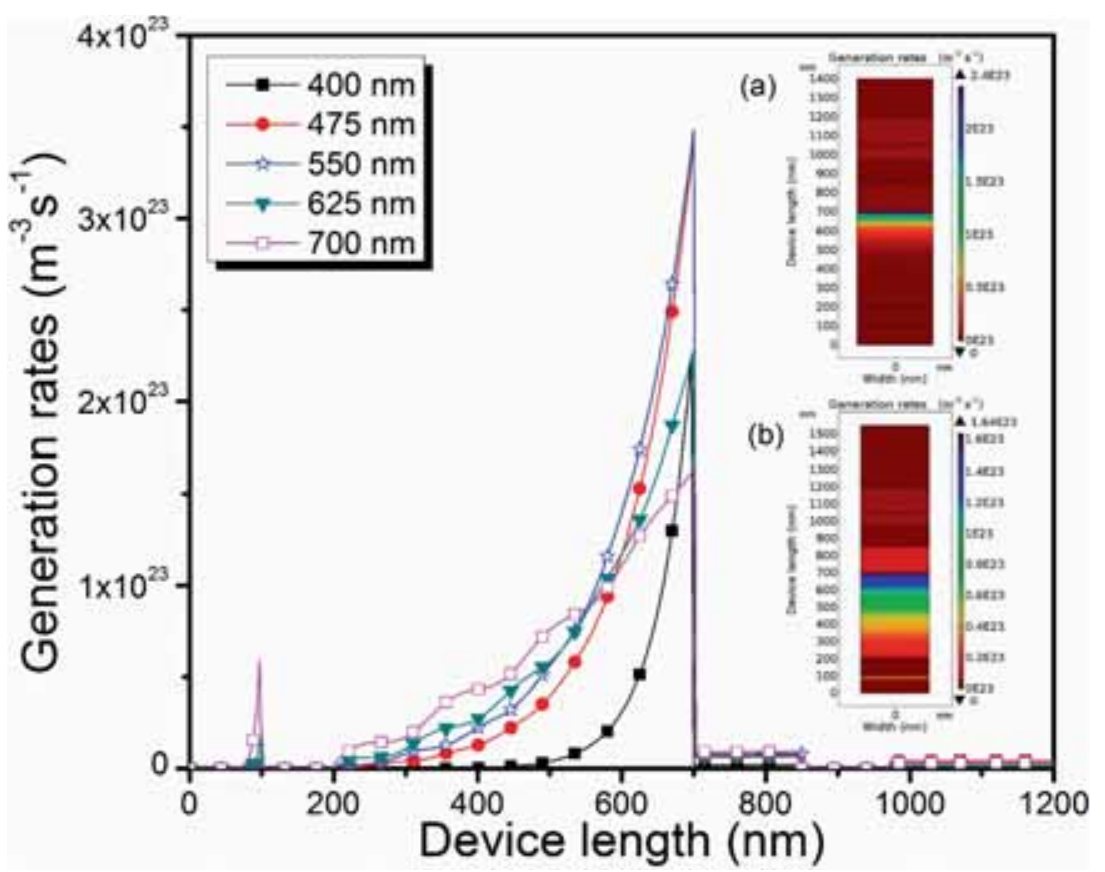

Figure 6. 1-D and (inset) 2-D cross-sectional generation rate profile inside the layer stack of the simulated solar cell at varied incident wavelengths.

$550 \mathrm{~nm}$. For comparison purposes, it may be of reader's interest that Rajib et al [50] have previously reported a generation rate of the order of $10^{26}$ in silicon-based PIN solar cells. Figure 6 (inset: $a$ and $b$ ) shows the cross-section of 2-D charge carrier generation profile in the perovskite solar cell for the transverse electromagnetic light at 400 and $700 \mathrm{~nm}$, respectively.

\section{Conclusion}

To summarize, we have developed a multiphysics model for perovskite-based solar cells by solving the Helmholtz equation in the FE-FD. A typical structure of a typical perovskite solar cell is presented together with the corresponding optical constants of its constituent layers. The mathematical model involved in optical modelling of the simulated solar cell is also presented and is capable of analysing light propagation at the nanometre scale. Using this model, we have successfully presented detailed light propagation and absorption profiles (one- and two-dimensional) in each constituent layer of the simulated solar cell (ITO $/ \mathrm{TiO}_{2} / \mathrm{ZnO} / \mathrm{CH}_{3}$ $\mathrm{NH}_{3} \mathrm{PbCl}_{3} /$ Spiro-OMeTAD/Al). From the distribution of the electromagnetic field and absorbed optical power, we have also numerically computed the effective charge generation rate within the photoactive perovskite layer as a function of the photon wavelength ranging from $400-700 \mathrm{~nm}$. The present study emphasizes critical basis and insightful guidelines for the futuristic development of a three-dimensional unified optoelectronic model coupled with a light-trapping scheme to achieve efficient perovskite-based solar cell design and optimization.

\section{Acknowledgements}

We are highly grateful to the Erasmus Mundus Intact (EMINTACT) mobility program for providing $\mathrm{PhD}$ fellowship for M N Shaikh.

\section{References}

[1] Eshaghi A and Aghaei A A 2015 Bull. Mater. Sci. 381177

[2] Siwach B, Mohan D, Sharma S and Jyoti D 2017 Bull. Mater. Sci. 401371

[3] Alwin S, Ramasubbu V and Shajan X S 2018 Bull. Mater. Sci. 4127

[4] Rakstys K, Paek S, Gao P et al 2017 J. Mater. Chem. A 57811

[5] Lin Q, Nagiri R C R, Burn P L and Meredith P 2017 Adv. Opt. Mater. 51600819

[6] Hutter E M, Hofman J J, Petrus M L et al 2017 Adv. Energy Mater. 71602349

[7] Jeon N J, Noh J H, Kim Y C, Yang W S, Ryu S and Seok S I 2014 Nat. Mater. 13897

[8] Niu G, Guo X and Wang L 2015 J. Mater. Chem. A 38970

[9] Green M A, Jiang Y, Soufiani A M and Ho-Baillie A 2015 J. Phys. Chem. Lett. 64774

[10] Grätzel M 2017 Acc. Chem. Res. 50487

[11] Green M A, Ho-Baillie A and Snaith H J 2014 Nat. Photonics 8 506 
[12] Kumar M S, Charanadhar N, Srikanth V V, Rao K B S and Raj B 2018 Bull. Mater. Sci. 4162

[13] Sakai N, Wang Z, Burlakov V M, Lim J, McMeekin D, Pathak S et al 2017 Small 131602808

[14] Correa-Baena J-P, Abate A, Saliba M, Tress W, Jacobsson T J, Grätzel M et al 2017 Energy Environ. Sci. 10710

[15] Kevin A B, Axel F P, Zhengshan Y, Mathieu B, Rongrong C, Jonathan P M et al 2017 Nat. Energy 217009

[16] Asghar M, Zhang J, Wang H and Lund P 2017 Renew. Sustain. Energy Rev. 77131

[17] Han G, Zhang S, Boix P P, Wong L H, Sun L and Lien S-Y 2017 Prog. Mater. Sci. 87246

[18] Kumar K R and Zeman M 2008 Bull. Mater. Sci. 31737

[19] Yagi T, Uraoka Y and Fuyuki T 2006 Sol. Energy Mater. Sol. Cells 902647

[20] Bierhoff T, Wallrabenstein A, Himmler A, Griese E and Mrozynski G 2001 IEEE Trans. Magn. 373307

[21] Rim S-B, Zhao S, Scully S R, McGehee M D and Peumans P 2007 Appl. Phys. Lett. 91243501

[22] Shaikh M, Acharya P and Papadakis A 2016 5th International Conference on Renewable Energy Sources \& Energy Efficiency-New Challenges, $\mathrm{p} 1$

[23] Parsons R, Tamang A, Jovanov V, Wagner V and Knipp D 2017 Appl. Sci. 7427

[24] Semenikhin I, Zanuccoli M, Benzi M, Vyurkov V, Sangiorgi E and Fiegna C 2012 Opt. Quant. Electron. 44149

[25] Lin Q, Armin A, Nagiri R C R, Burn P L and Meredith P 2015 Nat. Photonics 9106

[26] Phillips L J, Rashed A M, Treharne R E, Kay J, Yates P, Mitrovic I Z et al 2016 Sol. Energy Mater. Sol. Cells 147327

[27] Miyazaki K, Matsuki N, Shinno H, Fujioka H, Oshima M and Koinuma H 1999 Bull. Mater. Sci. 22729

[28] Ong K G, Varghese O K, Mor G K, Shankar K and Grimes C A 2007 Sol. Energy Mater. Sol. Cells 91250

[29] Fell A 2013 IEEE Trans. Electron. Devices 60733

[30] Isabella O, Solntsev S, Caratelli D and Zeman M 2013 Prog. Photovolt. Res. Appl. 2194
[31] Thiele E S and French R H 1998 J. Am. Ceram. Soc. 81469

[32] Ziang X, Shifeng L, Laixiang Q, Shuping P, Wei W, Yu Y et al 2015 Opt. Mater. Express 529

[33] Choi J J, Yang X, Norman Z M, Billinge S J and Owen J S 2013 Nano Lett. 14127

[34] Grätzel M 2014 Nat. Mater. 13838

[35] Hossain M F, Faisal M and Okada H 2016 2nd International Conference on Electrical, Computer \& Telecommunication Engineering (ICECTE), p 1

[36] Lin Q, Armin A, Nagiri R C R, Burn P L and Meredith P 2015 Nat. Photonics 9106

[37] Liu D and Kelly T L 2014 Nat. Photonics 8133

[38] Lin A and Phillips J 2008 Sol. Energy Mater. Sol. Cells 92 1689

[39] Yu L, Misra S, Wang J, Qian S, Foldyna M, Xu J et al 2014 Sci. Rep. 44357

[40] Muchuweni E, Sathiaraj T and Nyakotyo H 2017 Heliyon 3 e00285

[41] König T A, Ledin P A, Kerszulis J, Mahmoud M A, El-Sayed M A, Reynolds J R et al 2014 ACS Nano 86182

[42] Filipič M, Löper P, Niesen B, De Wolf S, Krč J, Ballif C et al 2015 Opt. Express 23 A263

[43] Phillips L J, Rashed A M, Treharne R E, Kay J, Yates P, Mitrovic I Z et al 2015 Data Brief 5926

[44] Gunaicha P P 2012 MS Thesis (Ohio: The University of Toledo)

[45] Sze S M and Ng K K 2006 Physics of semiconductor devices (USA: John Wiley \& Sons)

[46] Hoppe H, Arnold N, Sariciftci N and Meissner D 2003 Sol. Energy Mater. Sol. Cells $\mathbf{8 0} 105$

[47] Malik H A, Aziz F, Asif M, Raza E, Najeeb M A, Ahmad Z et al 2016 J. Lumin. 180209

[48] Zafar Q, Najeeb M A, Ahmad Z and Sulaiman K 2015 J. Nanopart. Res. 17372

[49] Ahmad Z, Abdullah S M, Zafar Q and Sulaiman K 2014 J. Mod. Opt. 611730

[50] Rajib M R, Rana S M, Hasan M R, Amin R, Iqbal M S, Anik M R et al 2014 Int. J. Eng. Res. Technol. 31 